\title{
Are three-sample tasks less sensitive than two-sample tasks? Memory effects in the testing of taste discrimination
}

\author{
SAMANTHA LAU and MICHAEL O'MAHONY \\ University of California, Davis, California \\ and \\ BENOÎT ROUSSEAU \\ Institute for Perception, Davis, California
}

\begin{abstract}
In order to provide insights into why discrimination protocols with three stimuli sometimes tend to be less sensitive than protocols with two stimuli, two experiments were conducted. In these experiments, the relative effects of memory decay and memory interference were investigated. Both experiments involved purified water and/or solutions of low NaCl concentration. In Experiment 1, three protocols were compared: the traditional same-different test (Protocol 1), the same protocol with a rinse between the two samples (Protocol 2), and Protocol 2 with an added time delay between the first sample and the intermediate rinse (Protocol 3.) The decrease in measured $d^{\prime}$ values as time delay increased indicated that memory decay might be a factor for tests with three stimuli, such as the triangle method, rendering it less sensitive than tests with two stimuli, such as the same-different method. In Experiment 2 , four protocols were compared: the traditional same-different test, the two-rinse same-different test, the triangle test, and what will be called duo same-different test. The experimental design allowed the individual consideration of memory decay and interference effects. From this last experiment, the substantial effect of memory interference was uncovered. Further experimentation will be necessary to estimate the exact relative effects of memory interference and memory decay.
\end{abstract}

To understand better the results obtained from discrimination methods, numerous comparisons of the power of a multitude of discrimination paradigms have been made. The most desirable test can be defined as a test with the greatest ability to detect a given sensory difference - that is, one with the highest statistical power. The first experimental approach was to compare the number of correct answers obtained with each test protocol and to estimate a protocol's discriminative power by its ability to reject the null hypothesis that the products are the same (see, e. g., Buchanan, Givon, \& Goldman, 1987; Byer \& Abrams, 1953; François \& Sauvageot, 1988; Gridgeman, 1955; MacRae \& Geelhoed, 1992). This approach does not provide information on the degree of difference between the products and does not explain some observed discrepant results among discrimination tests such as the paradox of discriminatory nondiscriminators (Byer \& Abrams, 1953; Gridgeman, 1970).

In order to ensure more generalizable results from discrimination testing, an alternative, more universal method

The authors thank M. Hautus and D. Noreen for their thorough review of this article, as well as for their helpful comments and advice, which improved its clarity and readability. Correspondence concerning this article should be addressed to B. Rousseau, Institute for Perception, 2306 Anza Avenue, Davis, CA 95616 (e-mail: ifpress@cs.com).

Note-This article was accepted by the previous editorial team, headed by Neil Macmillan. of analysis, based on Thurstone's (1927) law of categorical judgment and signal detection theory (SDT; Green \& Swets, 1966), has been applied (see, e.g., Delwiche \& O’Mahony, 1996; Frijters, 1979; Geelhoed, MacRae, \& Ennis, 1994; Hautus \& Irwin, 1995; Irwin, Hautus, \& Stillman, 1992; Masuoka, Hatjopoulos, \& O’Mahony, 1995; Rousseau \& O'Mahony, 1997; Stillman, 1993). A measure of the degree of difference, usually referred to as $\delta$ or $d^{\prime}$ ( $\delta$ is the population parameter, $d^{\prime}$ its estimate from the sample tested), among products can readily be obtained by using widely available tables (Elliott, 1964; Ennis, 1993; Frijters, 1981; Frijters, Kooistra, \& Vereijken, 1980; Hacker \& Ratcliff, 1979; Kaplan, Macmillan, \& Creelman, 1978; Rousseau \& Ennis, 2001). The variance of $d^{\prime}$ can also be estimated (Bi, Ennis, \& O'Mahony, 1997; Gourevitch \& Galanter, 1967; Miller, 1996), which permits statistical considerations, such as the significant differences among products or among several $d^{\prime}$ values. This index of discriminability presents an attractive feature, since it is constant across methods, provided that experimental variables, such as memory and sensory adaptation, do not interfere with the measurement. It offers a reliable theoretical basis for comparing the power of discrimination methods (Ennis, 1993).

The Thurstonian and SDT models are based on two assumptions: the variability of the sensory perception and the use of a decision rule to generate an answer. For a given sensory difference (i.e., $d^{\prime}$ value), discrimination tests 
using a more efficient decision rule, such as the twoalternative forced-choice (2AFC) and 3AFC protocols (skimming strategy; O’Mahony, Masuoka, \& Ishii, 1994) are statistically more powerful (less likely to miss a difference when it exists) than the traditional triangle (oddity) and duo-trio protocols (differencing, or comparisonof-distances strategy; O'Mahony et al., 1994), which use a less efficient decision rule. (The duo-trio test can be seen as a reversed $\mathrm{ABX}$ design: The subject is first presented with one reference and then with two stimuli and is required to indicate which of the two is the same as the reference.)

However, these models do not take into account the effect of experimental variables, psychological or physiological, on discrimination abilities. Such variables include relative memory requirements, sensory adaptation, and irritation. Their influence, if not negligible, will be to increase the variability of the sensory perceptions, thus reducing the discrimination ability of a given protocolthat is, the estimated $d^{\prime}$ value.

Previous research has indicated that protocols with three samples tend to yield lower $d^{\prime}$ values than do protocols with two samples. This has been observed with the 2AFC and 3AFC tests (Dessirier \& O'Mahony, 1999; Rousseau \& O'Mahony, 1997) and with the triangle and same-different tests (Rousseau, Meyer, \& O’Mahony, 1998; Rousseau \& O'Mahony, 2000, 2001; Rousseau, Rogeaux, \& O'Mahony, 1999; Stillman \& Irwin, 1995). The objective of the present research was to investigate the possible reasons for such an advantage for two-sample protocols. As was mentioned earlier, candidates potentially providing an explanation for this advantage are memory, sensory adaptation, and irritation effects.

Memory can have a significant effect on discrimination. When a sensory discrimination test involving the assessment of chemical stimuli is performed, the sample presentation is usually sequential (for an example of simultaneous stimulus presentation on distinct parts of the tongue, see Dessirier, O’Mahony, \& Carstens, 1997; McBurney, Kasschau, \& Bogart, 1967). This specific presentation design requires that the successive stimulus sensations be stored into memory until all samples have been tasted and a comparison with the memorized sensations can be completed, so as to generate the response to the task on hand. When the brief period of time over which a traditional discrimination test is performed is considered, the short-term component of memory (White, 1998) is most likely the one used during such a procedure. Unfortunately, the scientific literature describing experiments conducted in order to investigate taste and smell memory mechanisms and their short-term component in particular is limited, especially as compared with their visual and auditory counterparts. Most of the research conducted on short-term memory for the chemical senses has focused on olfactory memory, even though taste and chemosensory mixtures have been used in some research (Algom \& Marks, 1989; Algom, Marks, \& Cain, 1993; Stevenson \& Prescott, 1997). Taste exper- iments have shown the close similarity of taste and smell memory mechanisms in studies involving mixtures of the two kinds of chemicals (Algom et al., 1993; Stevenson \& Prescott, 1997).

When a sensory discrimination test is performed, the delay between the tasting of the samples is a matter of seconds, not the minutes or hours usually used in most of the olfactory memory experiments described before. Jehl, Royet, and Holley (1994) investigated what they called the very short term component for odors. In this experiment, a paradigm analogous to the same-different test was used, with delays between the two samples varying between 2 and $300 \mathrm{sec}$. When the pairs of samples that were compared were qualitatively very different, no decrease in performance was observed over time. This confirmed previously observed results (Engen, Kuisma, \& Eimas, 1973; Mair, Capra, McEntee, \& Engen, 1980). On the other hand, when similar samples were compared, a design close to that usually encountered in sensory discrimination testing, a decrease of performance was observed, illustrated by an increasing proportion of misses (the subjects responded same when pairs of different samples were presented). This decrease in performance agrees with experiments performed by Cubero, Avancini, and O'Mahony (1995) and Avancini, Cubero, and O'Mahony (1999), showing a similar decrease in performance following an increase in interstimulus delay from $0 \mathrm{sec}$ to up to 1 day. Testing other sensory modalities (visual and auditory), Kinchla and Smyzer (1967) found that a delay of $0.5 \mathrm{sec}$ was sufficient to decrease subjects' performance, as compared with the condition in which no time delay was inserted.

The effect described thus far assumes that forgetting occurs as a result of the automatic fading of the memory trace. This is the reasoning applied in trace decay theory (Baddeley, 1997). The same author describes an alternative theory: interference theory. In this case, "forgetting reflects the disruption of the memory trace by other traces, with the degree of interference depending on the similarity of the two mutually interfering memory traces" (p. 32). Memory interference can be divided into two categories: retroactive and proactive interference. Retroactive interference describes the fact that previously stored memories will be less readily retrieved because of the interaction of subsequently acquired information. The opposite can also occur, inducing a case of proactive interference. Research has been reported in the literature indicating the existence of both types of interference in the sensory olfactory modality (Köster, Degel, \& Piper, 2002; Lawless \& Engen, 1977; Walk \& Johns, 1984).

One goal of the present research was to confirm the potential effect of memory, as well as to investigate the relative role of each of its components (memory decay and interference) in discrimination testing.

The second experimental variable that may have an effect on discrimination testing performance is sensory adaptation. This effect occurs because of the stimulus carryover from one tasting to the next. Traditionally con- 
sidered, Thurstonian modeling and SDT make the assumption that the perceptions of all stimuli are independent. Therefore, the order in which the samples are evaluated does not influence the outcome of a trial, unless position biases happen to exist. Although it might be a valid assumption for visual and auditory stimuli, it might not hold with chemical stimuli, such as tastants and odorants. Numerous experiments have been conducted in which the influence of sequence effects on discrimination testing performance has been investigated (Dessirier \& O’Mahony, 1999; Masuoka et al., 1995; O'Mahony \& Goldstein, 1986; O'Mahony \& Odbert, 1985; Rousseau \& O’Mahony, 1997; Tedja, Nonaka, Ennis, \& O'Mahony, 1994). These sequence effects illustrate the fact that a Stimulus A might not elicit the same perceptual sensation if tasted after itself or tasted after the alternative Stimulus B. A Thurstonian model involving four perceptual distributions, to take into account adaptation effects, has been developed for the triangle and $3 \mathrm{AFC}$ tests (Ennis \& O'Mahony, 1995). In these experiments, adaptation was found to be one potential explanatory factor for the performance advantage of some two-sample protocols over their three-sample counterparts.

In the present experiments, we investigated further the relative importance of both memory and adaptation effects on the sometimes observed higher performance of a two-sample over a three-sample protocol. The protocols studied here were the same-different and the triangle tests. In the first experiment, we investigated the effect of time delay without memory interference on performance in the same-different test. Three protocols were compared: same-different with the second sample tasted immediately after the first, same-different with an intermediate rinse between the two samples, and samedifferent with an intermediate rinse and additional time delay between the samples. In the second experiment, we compared the triangle test with three versions of the same-different test: traditional design - two-rinse samedifferent, and what is defined here as the duo samedifferent - and investigated the potential role played by memory interference in a protocol's sensitivity.

\section{EXPERIMENT 1}

\section{Method}

Subjects. Twenty-four subjects (11 males and 13 females; age range, 20-26 years) participated in the experiment. They were students, friends, and staff affiliated with the Department of Food Science and Technology at the University of California at Davis. The subjects fasted, except for water, for at least $1 \mathrm{~h}$ prior to the experiment.

Stimuli. The subjects were required to discriminate between two stimuli: a low-concentration $\mathrm{NaCl}$ solution and purified water. The $\mathrm{NaCl}$ solutions were made from reagent grade sodium chloride dissolved in Millipore-purified water (Milli-Q system, Millipore Corp., Bedford, MA) with specific conductivity $(<10-6 \mathrm{mho} / \mathrm{cm}$, and surface tension of $\geq 71$ dynes $/ \mathrm{cm}$ ). Salt concentration was constant for a given judge and ranged from $3 \mathrm{mM}$ to $5 \mathrm{mM}$ across judges. Ten (10) $\mathrm{ml}$ aliquots of stimuli were dispensed in 1-oz transparent noncoded plastic portion cups (S. E. Rykoff \& Co., Los Angeles) using Oxford adjustable dispensers (Lancer, St. Louis). They were served at constant room temperature $\left(15^{\circ}-18^{\circ} \mathrm{C}\right)$. The whole aliquot was sipped and expectorated.

Procedure. Each subject performed 44 sets of each of the following three protocols: same-different test without time delay between the two samples, same-different test with one rinse between the samples, and same-different test with a rinse and time delay between the two samples. These 44 sets of each protocol were spread over five experimental sessions, with a practice session beforehand. In the first four sessions, the judges performed nine trials of each protocol, whereas in the last session only 8 tests per protocol were performed, for a total of 44 tests. All possible orders of tasting for each test were used an equal number of times; thus, each of the four orders occurred 11 times. Presentation order of the protocols was counterbalanced over the 24 judges.

At the beginning of the practice session, five rinses with distilled water were taken to cleanse the mouth.

For each of the three protocols, the judge was presented with four portion cups, each containing $10 \mathrm{ml}$ of liquid; the sequences of tasting are shown in Table 1 . The judge would take the content into the mouth and then expectorate it. Some of the cups contained taste stimuli that were assessed for their taste by the judge. Other cups contained mere rinses, which were used to cleanse the palate and whose sensory characteristics were accordingly not assessed. Yet whether the cups were to be used as stimuli or rinses varied with the protocols. Also, sometimes the rinses were purified water, and sometimes they were low-concentration $\mathrm{NaCl}$ solutions. The rinses were chosen to equalize the sequence of tasting and, thus, the adaptation conditions over the three protocols. It can be seen from Table 1 that each protocol used the same four presentations of purified water and low-concentration $\mathrm{NaCl}$.

For the same-different test without a time delay, the subject was instructed to rinse, using the first two cups, and was told that these samples were not part of the test and, thus, their sensory characteristics should be ignored. Then the judge was instructed to taste from the two remaining cups and state whether the stimuli were the same (both water or both salt) or different (one water and one salt). Sureness judgments were also required (sure vs. not sure).

Table 1

Experiment 1: Sequences of Tasting for Each Protocol Presented to Each Judge

Protocol 1

Same-Different Without Time Delay

$\begin{array}{cccc}w & w & \mathbf{W} & \mathbf{W} \\ s & s & \mathbf{S} & \mathbf{S} \\ w & w & \mathbf{W} & \mathbf{S} \\ s & s & \mathbf{S} & \mathbf{W}\end{array}$

Protocol 2

Same-Different With One Rinse Before Each Sample

$\begin{array}{cccc}w & \mathbf{W} & w & \mathbf{W} \\ s & \mathbf{S} & s & \mathbf{S} \\ w & \mathbf{W} & w & \mathbf{S} \\ s & \mathbf{S} & s & \mathbf{W}\end{array}$

Protocol 3

Same-Different With One Rinse Before Each Sample and Time Delay

$\begin{array}{cccc}w & \mathbf{W} & w & \mathbf{W} \\ s & \mathbf{S} & s & \mathbf{S} \\ w & \mathbf{W} & w & \mathbf{S} \\ s & \mathbf{S} & s & \mathbf{W}\end{array}$

Note-Each sequence was performed 11 times by each judge (total of 44 tests of each protocol). Small italicized letters indicate rinses, while bold capital letters indicate samples compared in the actual samedifferent test. S, salt solution; W, water. 
The second protocol was designed to investigate the effect of time delay. It could have been suitable to simply ask the judge to pause for a few seconds in between samples and see the effect on performance. However, during this pause, sensory adaptation might have changed, thus hindering the actual evaluation of the effect of memory delay. Taking a rinse during the pause maintained the same adaptation conditions as those in the first protocol. Accordingly, the judge was instructed to rinse using the first cup, taste the stimulus in the second cup, rinse using the third cup, and then taste the stimulus in the fourth cup. The judge was required to compare the two stimuli (second and fourth cups) and perform a same-different task as described above. The characteristics of the two rinses were to be ignored.

The time it took for a judge to take a sip and expectorate a sample was recorded with a timer. The average time was used for the purpose of the third protocol. Its design was the same as that of the second protocol but included a pause between the second and the third cups. This approach was to provide more information on the effect of the time delay. Thus, for the same-different test with a time delay, the judge was instructed to rinse from the first cup and then taste the stimulus in the second cup. After expectorating this stimulus, the judge would hear a beep and was instructed to wait until a second beep was heard before proceeding to the next cup. At that time, a rinse was taken from the third cup, followed by the second stimulus in the fourth cup. A same-different task between the two stimuli was performed as described above. The time between the first and the second beeps was the average time for the judge to sip and expectorate one sample. The range of the time delay was between 4 and 6 secs. This allowed specific consideration of memory delay effects independent of memory interference and adaptation effects.

\section{Results}

For all three versions of the same-different test, the computing approach described in Macmillan and Creelman (1991) could be used to estimate the corresponding $d^{\prime}$ values. For this research, the authors used the degree of difference program from the IFPrograms software (Institute for Perception, Richmond, VA), since it provides both the $d^{\prime}$ values and their variances for each of the protocols. The analysis was applied to difference ratings and used the method of maximum likelihood to estimate $d^{\prime}$, $\tau$ (the cognitive criterion used by the subject to generate an answer), and the variance-covariance matrix for these estimates. This analysis assumes the differencing, rather than the independent observation, model; its appropriateness is confirmed by the slope of about 2 obtained when using the normal coordinates of their corresponding receiver-operating characteristic curves. Table 2 gives the mean $d^{\prime}$ values of each protocol over the 24 judges. An analysis of variance indicates significant differences between the protocols $[F(2,46)=5.84, p=.006]$. Multiple comparisons show a significant decrease of sensitivity between Protocols 1 and 3, whereas Protocol 2 shows an intermediate sensitivity and is not significantly different from either.

By looking at the frequencies of each category of responses in Table 2, it can be seen that the increase in perceptual variance due to time delay has the effect mainly of increasing the proportion of times identical stimuli are called different (in order to make the table easier to read, the categories sure and not sure are combined, as are those of the two different pairs and two identical pairs). A model based on an increase of the perceptual variances due to memory successfully accounts for these results. It can be illustrated using the Thurstonian/signal detection approach to calculate a $d^{\prime}$ value from this paradigm (cf. O'Mahony \& Rousseau, 2003) and is shown in the Appendix. The model shows how a single parameter can be estimated ( $m=1.61)$ to account for the change in $d^{\prime}$ values, whereas the criterion location can be assumed as being fixed. This would illustrate the constant decision rule used by the subjects, even though the time delay varied from Protocol 1 through Protocol 3.

Also, strong sequence effects were observed. Tables $3 \mathrm{~A}$ and $3 \mathrm{~B}$ give the response frequencies of the four possible sequences described in Table 1 . Since the same trend was observed in all three protocols, their respective sequence frequencies were combined in Table 3B. The WWWS sequence was the most efficient, probably because of a context effect. Adaptation would render the last sample as particularly salty, since it was preceded by three water stimuli (O'Mahony, 1979). An analogous effect was reported by Dessirier and O'Mahony (1999). The SSSW sequence appears to be less sensitive. This can be explained again by adaptation. Either the second or the third S sample was the target to be compared with the last $\mathrm{W}$ sample, and since they were preceded by an $\mathrm{S}$ sample, their perceived saltiness would have decreased,

Table 2

Experiment 1: Frequencies of Responses Same and Different for Each of the Three Protocols Combined Over the 24 Judges, With Mean $d^{\prime}$ Values and Standard Errors for the Three Protocols Over the 24 Judges

\begin{tabular}{|c|c|c|c|c|c|c|}
\hline \multirow[b]{2}{*}{ Presentation } & \multicolumn{2}{|c|}{$\begin{array}{c}\text { Protocol } 1 \\
\text { Same-Different Without } \\
\text { Time Delay }\end{array}$} & \multicolumn{2}{|c|}{$\begin{array}{c}\text { Protocol } 2 \\
\text { Same-Different With } \\
\text { One Rinse Before Each } \\
\text { Sample }\end{array}$} & \multicolumn{2}{|c|}{$\begin{array}{c}\text { Protocol } 3 \\
\text { Same-Different With } \\
\text { One Rinse Before Each } \\
\text { Sample and Time Delay }\end{array}$} \\
\hline & Different & Same & Different & Same & Different & $\overline{\text { Same }}$ \\
\hline Different & 347 & 181 & 348 & 180 & 337 & 191 \\
\hline Same & 62 & 466 & 94 & 434 & 119 & 409 \\
\hline Mean $d^{\prime}$ value & \multicolumn{2}{|c|}{$2.80 *$} & \multicolumn{2}{|c|}{$2.65 * \dagger$} & \multicolumn{2}{|c|}{$2.39 \dagger$} \\
\hline Standard error & \multicolumn{2}{|c|}{0.09} & \multicolumn{2}{|c|}{0.18} & \multicolumn{2}{|c|}{0.15} \\
\hline
\end{tabular}

*†Means with common superscripts are not significantly different. 
Table 3A

Experiment 1: Response Frequencies for All Four Possible Sequences for Each of the Three Protocols

\begin{tabular}{lrcrr}
\hline & \multicolumn{4}{c}{ Response } \\
\cline { 2 - 5 } & $\begin{array}{c}\text { Different } \\
\text { Sure }\end{array}$ & $\begin{array}{l}\text { Different } \\
\text { Not Sure }\end{array}$ & $\begin{array}{c}\text { Same } \\
\text { Not Sure }\end{array}$ & $\begin{array}{r}\text { Same } \\
\text { Sure }\end{array}$ \\
\hline Protocol 1 & & & & \\
wwWS & 221 & 30 & 5 & 8 \\
ssSW & 33 & 63 & 76 & 92 \\
wwWW & 7 & 26 & 74 & 157 \\
ssSS & 7 & 22 & 106 & 129 \\
Protocol 2 & & & & \\
wWwS & 226 & 20 & 14 & 4 \\
sSsW & 43 & 59 & 69 & 93 \\
wWwW & 11 & 29 & 99 & 125 \\
sSsS & 13 & 41 & 104 & 106 \\
Protocol 3 & & & & \\
wWwS & 220 & 27 & 11 & 6 \\
sSsW & 32 & 58 & 81 & 93 \\
sSsS & 15 & 47 & 98 & 104 \\
\hline
\end{tabular}

Note-S, salt solution; W, water solution.

Table 3B

Experiment 1: Response Frequencies for All Four Possible Sequences (Responses Combined Over the Three Protocols)

\begin{tabular}{lccccr}
\hline & & \multicolumn{4}{c}{ Response } \\
\cline { 3 - 6 } Sequence & & $\begin{array}{c}\text { Different } \\
\text { Sure }\end{array}$ & $\begin{array}{c}\text { Different } \\
\text { Not Sure }\end{array}$ & $\begin{array}{c}\text { Same } \\
\text { Not Sure }\end{array}$ & $\begin{array}{r}\text { Same } \\
\text { Sure }\end{array}$ \\
\hline wwWS & $N$ & 667 & 77 & 30 & 18 \\
wWwS & $\%$ & 84 & 10 & 4 & 2 \\
ssSW & $N$ & 108 & 180 & 226 & 278 \\
SSsW & $\%$ & 14 & 23 & 28 & 35 \\
wwWW & $N$ & 32 & 98 & 262 & 400 \\
wWwW & $\%$ & 4 & 12 & 33 & 51 \\
ssSS & $N$ & 35 & 110 & 308 & 339 \\
sSsS & $\%$ & 4 & 14 & 39 & 43 \\
\hline Not
\end{tabular}

Note- $N$, for each sequence, total number of each answer; $\%$, for each sequence, percentage of each answer; $\mathrm{S}$, salt solution; $\mathrm{W}$, water solution.

allowing them to be mistaken for water samples. A similar effect would be expected to occur for the SSSS sequence, where all the target stimuli might be perceived as only slightly salty or tasteless and yet be perceived correctly as same.

\section{EXPERIMENT 2}

Both memory delay and interference can have a damaging effect during a discrimination test: the more numerous the samples in the trial, the longer their perceived sensations need to be stored in memory, and the higher the probability that the stimulus memories will fade before a decision will be made according to the instructions given. It is to be noted that protocols with the same number of samples can also exhibit different sensitivities, depending on slight changes in the order of stimulus presentation. This was reported in the duo-trio paradigm (reversed ABX) for which the presentation of the reference between the two alternatives reduced memory requirements, as compared with the traditional design involving presentation of the reference before the two alternatives (Rousseau, Stroh, \& O'Mahony, 2002). The former protocol was found to be more discriminating than the latter.

Experiment 2 compared the triangle (oddity) and the same-different tests, as well as two other procedures presenting intermediate levels of memory and adaptation. The triangle method has two potential disadvantages in terms of memory, as compared with the same-different method. The first one is due to memory delay. In a triad, the three samples are evaluated successively. Therefore, the third sample cannot be compared immediately after the first sample and will need to rely on a memory trace that might have decayed during the time of the second sample evaluation. The second issue is that of memory interference. Once the third sample has been evaluated, its sensation needs to be compared with those of the first and second stimuli; those memory traces may interfere with one another, rendering sensation retrieval and comparisons more difficult and, thus, reducing performance.

In order to investigate the effect of memory interference, independently from memory delay, as a potential reason for the lower sensitivity observed sometimes in the triangle test, the duo same-different method was introduced. It consists of a traditional two-stimulus samedifferent test in which the two stimuli are preceded by a third sample. The subject needs to state whether the last two stimuli were the same or different and whether the first stimulus was the same as the second or the third stimulus or was different from both. This strategy mimics that used by a judge in a triangle test. However, the considered answer is only that given for the last two stimuli. There will be no memory delay issue, although the memory trace of the first stimulus might hinder by interference the comparison of the last two stimuli. Therefore, its sensitivity is predicted to be intermediate between those of the traditional same-different and the triangle tests. The sequences of tasting for the protocols are shown in Table 4.

From Table 4, it can be seen that the order of presentation for the triangle and the duo same-different tests was the same whether they were stimuli or rinses. This equalized adaptation conditions between the two protocols. However, comparison was also to be made with a regular same-different test, and the presentation sequence was different. So a fourth protocol, a two-rinse samedifferent test, was introduced to equalize the order with those of the triangle and the duo same-different tests. As in Experiment 1, the nature of the rinse could vary.

There was one more aspect to the design of Experiment 2. In order to obtain more than one comparison among the protocols, a total of three samples were involved, labeled $A, B$, and $C$. Three comparisons were performed with each protocol (A vs. B, A vs. C, and B 
vs. C). All three were salt solutions at different concentrations, A being the lowest and $\mathrm{C}$ the highest. This permitted a more thorough investigation of the performance of each procedure.

\section{Method}

Subjects. Eighteen subjects ( 8 males and 10 females; age range, $18-26$ years) participated in the experiment. They were chosen from the same pool of consumers as that in Experiment 1. However, none of the subjects had participated in Experiment 1. The subjects fasted, except for water, for at least $1 \mathrm{~h}$ prior to the experiment.

Stimuli. The stimuli used were prepared using the same method and materials as those in Experiment 1. The concentrations of $\mathrm{NaCl}$ solutions were chosen from one of three different sets, depending on the subjects' discrimination abilities estimated during a preliminary session: Set 1 (A, $4 \mathrm{mM}$; B, $8 \mathrm{mM}$; C, $12 \mathrm{mM}$ ), Set 2 (A, $5 \mathrm{mM}$; B, $8 \mathrm{mM}$; C, $11 \mathrm{mM}$ ), or Set 3 (A, $5 \mathrm{mM}$; B, $10 \mathrm{mM}$; , $15 \mathrm{mM}$ ).

Procedure. For each pair of stimuli AB, AC, and BC, the subjects performed 16 sets of each of the following four protocols: same-different test, two-rinse same-different test, duo samedifferent test, and triangle test. Sample presentation order was arranged so that the sequences of tasting, adaptation conditions, and time delay were identical across the latter three protocols (see Table 4). These 16 sets of each pair and protocol were spread over eight experimental sessions, with a practice session beforehand. During each session, the judges performed six of each protocol, consisting of two of each of the three stimulus pairs. Care was taken to counterbalance the orders of presentation of the stimuli and the protocols.

\section{Table 4}

Experiment 2: Sequences of Tasting for Each Protocol Presented to Each Judge for the AB Pair of Stimuli Same-Different

$\begin{array}{lll}a & \mathbf{A} & \mathbf{B} \\ a & \mathbf{B} & \mathbf{A} \\ a & \mathbf{A} & \mathbf{A} \\ a & \mathbf{B} & \mathbf{B}\end{array}$

Two-Rinse Same-Different

$\begin{array}{llll}a & a & \mathbf{A} & \mathbf{B} \\ a & a & \mathbf{B} & \mathbf{A} \\ a & b & \mathbf{A} & \mathbf{B} \\ a & b & \mathbf{B} & \mathbf{A} \\ a & b & \mathbf{A} & \mathbf{A} \\ a & a & \mathbf{B} & \mathbf{B}\end{array}$

Duo Same-Different

$\begin{array}{llll}a & \underline{a} & \mathbf{A} & \mathbf{B} \\ a & \underline{a} & \mathbf{B} & \mathbf{A} \\ a & \underline{b} & \mathbf{A} & \mathbf{B} \\ a & \underline{b} & \mathbf{B} & \mathbf{A} \\ a & \underline{b} & \mathbf{A} & \mathbf{A} \\ a & \underline{a} & \mathbf{B} & \mathbf{B}\end{array}$

Triangle

$\begin{array}{llll}a & \mathbf{A} & \mathbf{A} & \mathbf{B} \\ a & \mathbf{A} & \mathbf{B} & \mathbf{A} \\ a & \mathbf{B} & \mathbf{A} & \mathbf{B} \\ a & \mathbf{B} & \mathbf{B} & \mathbf{A} \\ a & \mathbf{B} & \mathbf{A} & \mathbf{A} \\ a & \mathbf{A} & \mathbf{B} & \mathbf{B}\end{array}$

Note-Small italicized letters indicate rinses; bold capital letters indicate the samples being compared in the actual test. In the duo samedifferent, the underlined sample denotes the reference.
Before the start of the session, the judges rinsed their mouths five times with distilled water. For the same-different protocol, three cups of liquid were presented to the judge. For the other three protocols, four cups were presented.

For the same-different test, the subject was instructed to take the first cup as a rinse and was told that this sample was not part of the test and, thus, its sensory characteristics should be ignored. Then the judge was asked to taste and assess the stimuli in the two remaining cups and state whether the stimuli were the same or different. Sureness judgments were also required.

For the two-rinse same-different test, the judge rinsed from the first two cups and then tasted and assessed the stimuli in the last two, performing a same-different task as described above.

For the duo same-different test, the judge was instructed to use the first cup for a rinse and taste and assess the stimuli in the three remaining cups. The judge was required to perform a same-different task between the last two samples and was also asked to compare the stimulus in the first cup with the remaining two. He/she was to determine whether it was the same as one of the two or different from both.

In the triangle protocol, the judge rinsed from the first cup and then tasted and assessed the stimuli in the remaining three. The instructions were to select the stimulus that was different from the other two.

\section{Results}

For all three versions of the same-different protocol, the approach described by Macmillan and Creelman (1991) could be used to estimate the corresponding $d^{\prime}$ values. For the triangle test, $d^{\prime}$ values could be obtained from published tables, such as those from Ennis (1993). In this research, the authors chose to use the IFPrograms software (Institute for Perception, Richmond, VA), since it provided both the corresponding $d^{\prime}$ values and their associated variances. For the three versions of the same-different test, the degree of difference program was used; as was mentioned earlier, this model assumes the differencing strategy. Even though alternative strategies might be available for the duo same-different test, the differencing strategy was assumed on the basis of informal observations and discussion with the subjects. For the triangle test, $d^{\prime}$ values were estimated using the corresponding program.

Due to the small number of judgments available to calculate $d^{\prime}$ values for the individual judges and the individual pairs of stimuli (12), some infinite $d^{\prime}$ values (ceiling effects) were observed for some judges, protocols, and pairs of stimuli. Consequently, a corrective value of 0.05 was added to all the cells of the matrix for the various versions of the same-different test, following an approach similar to that proposed by Macmillan and Creelman (1991). This had the effect of eliminating ceiling effects and decreasing only slightly the $d^{\prime}$ values. An analogous modification was applied for the triangle test. The pooled raw data for the three same-different tests are shown in Table 5.

A three-way analysis of variance (subject, protocol, and pair of stimuli) was conducted, and significant differences were observed among the $d^{\prime}$ values from the three protocols $[F(3,102)=11.8, p<.001]$. A Tukey test, used to guard against Type I error, indicated that the $d^{\prime}$ values from the two-rinse same-different and same-different protocols were significantly higher than those obtained with the duo 
Table 5

Experiment 2: Pooled Raw Data for All Three Same-Different Protocols

\begin{tabular}{|c|c|c|c|c|c|}
\hline \multirow[b]{2}{*}{$\underline{\text { Stimulus }}$} & \multirow[b]{2}{*}{ Pair } & \multicolumn{4}{|c|}{ Response } \\
\hline & & $\begin{array}{c}\text { Different } \\
\text { Sure }\end{array}$ & $\begin{array}{l}\text { Different } \\
\text { Not Sure }\end{array}$ & $\begin{array}{c}\text { Same } \\
\text { Not Sure }\end{array}$ & $\begin{array}{l}\text { Same } \\
\text { Sure }\end{array}$ \\
\hline \multicolumn{6}{|c|}{ Two-Rinse Same-Different } \\
\hline \multirow{2}{*}{$\mathrm{AB}$} & $\mathrm{D}$ & 67 & 30 & 28 & 19 \\
\hline & $\mathrm{S}$ & 18 & 11 & 42 & 73 \\
\hline \multirow{2}{*}{$\mathrm{AC}$} & $\mathrm{D}$ & 118 & 19 & 5 & 2 \\
\hline & $\mathrm{S}$ & 18 & 15 & 40 & 71 \\
\hline \multirow{2}{*}{$\mathrm{BC}$} & $\mathrm{D}$ & 64 & 43 & 23 & 14 \\
\hline & $\mathrm{S}$ & 21 & 19 & 46 & 58 \\
\hline \multirow{2}{*}{ Total } & D & 249 & 92 & 56 & 35 \\
\hline & $\mathrm{S}$ & 57 & 45 & 128 & 202 \\
\hline \multicolumn{6}{|c|}{ Same-Different } \\
\hline \multirow{2}{*}{$\mathrm{AB}$} & $\mathrm{D}$ & 60 & 33 & 30 & 21 \\
\hline & S & 31 & 45 & 80 & 132 \\
\hline \multirow{2}{*}{$\mathrm{AC}$} & $\mathrm{D}$ & 119 & 19 & 2 & 4 \\
\hline & $\mathrm{S}$ & 38 & 31 & 74 & 145 \\
\hline \multirow{2}{*}{$\mathrm{BC}$} & D & 78 & 31 & 19 & 16 \\
\hline & $\mathrm{S}$ & 51 & 56 & 84 & 97 \\
\hline \multirow{2}{*}{ Total } & D & 257 & 83 & 51 & 41 \\
\hline & $\mathrm{S}$ & 120 & 132 & 238 & 374 \\
\hline \multicolumn{6}{|c|}{ Duo Same-Different } \\
\hline \multirow{2}{*}{$\mathrm{AB}$} & $\mathrm{D}$ & 57 & 27 & 32 & 28 \\
\hline & $\mathrm{S}$ & 25 & 37 & 24 & 58 \\
\hline \multirow{2}{*}{$\mathrm{AC}$} & D & 118 & 10 & 6 & 10 \\
\hline & $\mathrm{S}$ & 23 & 18 & 29 & 74 \\
\hline \multirow{2}{*}{$\mathrm{BC}$} & D & 72 & 33 & 23 & 16 \\
\hline & $\mathrm{S}$ & 38 & 22 & 29 & 55 \\
\hline \multirow{2}{*}{ Total } & D & 247 & 70 & 61 & 54 \\
\hline & $\mathrm{S}$ & 86 & 77 & 82 & 187 \\
\hline
\end{tabular}

Note-D, different; S, same.

same-different and triangle protocols (cf. Table 6). The same trend was observed at the individual pair level.

Over the four protocols, $d^{\prime}$ values for the $\mathrm{AB}, \mathrm{BC}$, and AC stimulus pairs were 1.97, 2.04, and 3.85, respectively. The first two $d^{\prime}$ values were not found to be significantly different from each other, whereas the third one was found to be significantly greater than the other two. It is worth noting that the expected additivity property seems to hold. The ratio $\left(d_{\mathrm{AB}}^{\prime}+d_{\mathrm{BC}}^{\prime}\right) / d_{\mathrm{AC}}^{\prime}$ should come to 1 if it were the case. By using the values reported above, the ratio was found to be 1.04, thus corroborating this expectation. Also, as in Experiment 1, some sequence effects were observed. Those effects were found for all four protocols.

\section{GENERAL DISCUSSION}

In Experiment 1, we investigated the effect of time delay in the same-different test. As time increased between the evaluations of the two target stimuli, discrimination decreased. By comparing Protocols 1 and 2 for the effect of memory decay with time, it can be argued that memory interference, as well as memory decay, hindered the subjects' performance when an intermediate rinse was added between the two target samples. Even if the judge was told to ignore the sensory characteristics of the rinse, it might still have interfered with the retrieval of the memory of the first sample of the pair.

By comparing the results from Protocols 2 and 3, with and without the delay, it can be concluded that memory decay was the reason for the observed lower performance in Protocol 3. If memory interference was the main effect, increasing time delay between the samples in Protocol 3 would not have changed the performance to such an extent; yet it did. Also, the extent of the decrease was comparable to that observed between Protocols 1 and 2 . Therefore, it can be argued that the decrease in performance when the rinse was added between the two target stimuli can be seen as being mainly an effect of memory decay; memory interference would seem to have played a minor role.

A more complex explanation could involve an immediate effect of memory interference (induced by the intermediate sample), whereas the effect of memory decay is not immediately apparent but slowly builds up to play a significant role when the time delay is longer. Further experimentation will be needed to investigate this hypothesis.

In Experiment 2, the proposed hypotheses seem to have been confirmed. The same-different (two-rinses) method had a significantly higher $d^{\prime}$ than did the duo same-different method, which had an added effect of memory interference. The difference between the $d$ 's for the same-different (two-rinses) method and the triangle method was even greater, the latter suffering from greater memory delay as well as interference. The difference between the triangle and the duo same-different methods, due to greater memory delay, was small. The samedifferent test without the two prior rinses varied slightly from the two-rinse same-different test because its adaptation conditions were different, indicating the importance of controlling such effects. The same-different

Table 6

Experiment 2: Mean $d^{\prime}$ Values (Over 18 Subjects) for Significant Differences and Standard Errors ( $S E$ s) for the Three Protocols Over the 18 Judges

\begin{tabular}{|c|c|c|c|c|c|c|c|c|}
\hline \multirow[b]{3}{*}{ Stimuli } & \multirow{2}{*}{\multicolumn{2}{|c|}{$\begin{array}{c}\text { Two-Rinse } \\
\text { Same-Different } \\
\end{array}$}} & \multirow{2}{*}{\multicolumn{2}{|c|}{ Same-Different }} & \multirow{2}{*}{\multicolumn{2}{|c|}{$\begin{array}{c}\text { Duo } \\
\text { Same-Different } \\
\end{array}$}} & \multirow{2}{*}{\multicolumn{2}{|c|}{ Triangle }} \\
\hline & & & & & & & & \\
\hline & $d^{\prime}$ & $S E$ & $d^{\prime}$ & $S E$ & $d^{\prime}$ & $S E$ & $d^{\prime}$ & $S E$ \\
\hline All pairs & $3.11 *$ & 0.19 & $2.84 *$ & 0.17 & $2.35 \dagger$ & 0.21 & $2.24 \dagger$ & 0.15 \\
\hline $\mathrm{AB}$ & 2.54 & 0.30 & 2.20 & 0.19 & 1.42 & 0.25 & 1.79 & 0.21 \\
\hline $\mathrm{AC}$ & 4.29 & 0.23 & 4.08 & 0.25 & 3.81 & 0.32 & 3.18 & 0.25 \\
\hline $\mathrm{BC}$ & 2.52 & 0.28 & 2.23 & 0.22 & 1.83 & 0.20 & 1.75 & 0.20 \\
\hline
\end{tabular}

*†Means with common superscripts are not significantly different. 
test's yielding higher $d^{\prime}$ values than the triangle test corroborated previous research (Rousseau et al., 1998; Rousseau et al., 1999). It had previously been thought that memory was the main reason for the higher sensitivity of the same-different test. The present research provided further insights into this issue.

The results observed would tend to indicate the significant role played by memory interference in the lower sensitivity of the triangle method, as compared with the same-different method, whereas memory decay seems to play only a minor role. Memory interference played a significant role, as shown by the significantly higher sensitivity of the two-rinse same-different test compared to that of the duo same-different test. On the other hand, the duo same-different and triangle tests' sensitivities were not found to be significantly different, thus tending to indicate the lack of strength of any effect of memory decay.

Therefore, this project provided possible insights into why protocols involving the comparison of two stimuli might be more discriminating than those involving the comparison of three stimuli. In past research, the $2 \mathrm{AFC}$ test has been found to be more discriminating than the 3AFC test (Dessirier \& O'Mahony, 1999; Rousseau \& O'Mahony, 1997), whereas the same-different method has been found to be superior in sensitivity to the triangle test (Rousseau et al., 1998; Rousseau et al., 1999). From the present experiments, it can be hypothesized that the main memory factor influencing such differences in sensitivity is memory interference.

There was a nonsignificant trend for the two-rinse same-different test to be more sensitive than the traditional same-different test (cf. Table 6). One potential explanation for such a trend is the adaptation effect observed with those particular stimuli and the sequences of tasting inherent to the protocols. The two-rinse samedifferent test exhibits a higher proportion of better sequences, as described by O'Mahony and Odbert (1985) and Rousseau et al. (1999).

It is worth noting that the size of the sensory differences investigated was fairly large (mean $d^{\prime}$ values equal or superior to 1.4). It might be of interest to study the same effects with more confusable stimuli pairs. As for the $2 \mathrm{AFC}$ and $3 \mathrm{AFC}$ tests, tasting sequences might also play a role, as was described in the above-mentioned research reports. Additional research will allow us to expand even further our understanding of the psychology and physiology of human perception and its application to the numerous areas of sensory science.

\section{REFERENCES}

Algom, D., \& Marks, L. E. (1989). Memory psychophysics for taste. Bulletin of the Psychonomic Society, 27, 257-259.

Algom, D., Marks, L. E., \& Cain, W. S. (1993). Memory psychophysics for chemosensation: Perceptual and mental mixtures of odor and taste. Chemical Senses, 18, 151-160.

Avancini, T. C. A., Cubero, E., \& O’Mahony, M. (1999). Samedifferent discrimination tests with interstimulus delays up to one day, Journal of Sensory Studies, 14, 1-18.
Baddeley, A. D. (1997). Human memory: Theory and practice (rev. ed.). Hove, U.K.: Psychology Press.

Bi, J., Ennis, D. M., \& O'Mahony, M. (1997). How to estimate and use the variance of $d^{\prime}$ from difference tests. Journal of Sensory Studies, 12, 87-104.

Buchanan, B., Givon, M. M., \& Goldman, A. (1987). Measurement of discrimination ability in taste tests: An empirical investigation. Journal of Marketing Research, 24, 154-163.

Byer, A. J., \& Abrams, D. (1953). A comparison of the triangular and two-sample taste-test methods. Food Technology, 7, 185-187.

Cubero, E., Avancini, T. C. A., \& O’Mahony, M. (1995). Cognitive aspects of difference testing: Memory and interstimulus delay. Journal of Sensory Studies, 10, 307-324.

Delwiche, J., \& O'Mahony, M. (1996). Flavour discrimination: An extension of Thurstonian paradoxes to the tetrad method. Food Quality \& Preference, 7, 1-5.

DESSIRIER, J. M., \& O'MAHONY, M. (1999). Comparison of $d^{\prime}$ values for the 2-AFC (paired comparison) and 3-AFC discrimination methods: Thurstonian models, sequential sensitivity analysis and power. Food Quality \& Preference, 10, 1-8.

Dessirier, J. M., O’MaHONY, M., \& CARSTEns, E. (1997). Oral irritant effects of nicotine: Psychophysical evidence for decreased sensation following repeated application and lack of cross-desensitization to capsaicin. Chemical Senses, 22, 483-492.

Elliotr, P. B. (1964). Tables of $d^{\prime}$. In J. A. Swets (Ed.), Signal detection and recognition by human observers: Contemporary readings (pp. 651-684). New York: Wiley.

Engen, T., Kuisma, J. E., \& Eimas, P. D. (1973). Short-term memory of odors. Journal of Experimental Psychology, 99, 222-225.

ENNIS, D. M. (1993). The power of sensory discrimination methods. Journal of Sensory Studies, 8, 353-370.

Ennis, D. M., \& O’Mahony, M. (1995). Probabilistic models for sequential taste effects in triadic choice. Journal of Experimental Psychology: Human Perception \& Performance, 21, 1088-1097.

FrançOIs, P., \& SauvageOt, F. (1988). Comparison of the efficiency of pair, duo-trio and triangle tests. Journal of Sensory Studies, 3, 81-94.

FrIJTERS, J. E. R. (1979). The paradox of discriminatory nondiscriminators resolved. Chemical Senses \& Flavor, 4, 355-358.

FrIJTERS, J. E. R. (1981). Expanded tables for conversion of a proportion of correct responses $(\mathrm{P})$ to the measure of sensory difference $\left(d^{\prime}\right)$ for the triangular method and the 3-alternative forced choice procedure. Journal of Food Science, 47, 139-143.

Frijters, J. E. R., Kooistra, A., \& VereiJKen, P. F. G. (1980). Tables of $d^{\prime}$ for the triangular method and the 3-AFC signal detection procedure. Perception \& Psychophysics, 27, 176-178.

Geelhoed, E. N., MacRae, A. W., \& Ennis, D. M. (1994). Preference gives more consistent judgments than oddity only if the task can be modeled as forced choice. Perception \& Psychophysics, 55, 473-477.

Gourevitch, V., \& Galanter, E. (1967). A significant test for one parameter isosensitivity functions. Psychometrika, 32, 25-33.

Green, D. M., \& Swets, J. A. (1966). Signal detection theory and psychophysics. New York: Wiley.

Gridgeman, N. T. (1955). Taste comparisons: Two samples or three? Food Technology, 9, 148-150.

Gridgeman, N. T. (1970). A re-examination of the two-stage triangle test for the perception of sensory differences. Journal of Food Science, 35, 87-91.

Hacker, M. J., \& Ratcliff, R. (1979). A revised table of $d^{\prime}$ for $M$ alternative forced choice. Perception \& Psychophysics, 26, 168-170.

Hautus, M. J., \& IRwin, R. J. (1995). Two models for estimating the discriminability of foods and beverages. Journal of Sensory Studies, 10, 203-215.

Irwin, R. J., Hautus, M. J., \& Stillman, J. A. (1992). Use of the receiver operating characteristic in the study of taste perception. Journal of Sensory Studies, 7, 291-314.

JeHL, C., RoYet, J.-P., \& Holley, A. (1994). Very short term recognition memory for odors. Perception \& Psychophysics, 56, 658-668.

Kaplan, H. L., Macmillan, N. A., \& Creelman, C. D. (1978). Tables of $d^{\prime}$ for variable-standard discrimination paradigms. Behavior Research Methods \& Instrumentation, 10, 796-813. 
Kinchla, R. A., \& Smyzer, F. (1967). A diffusion model of perceptual memory. Perception \& Psychophysics, 2, 219-229.

Köster, E. P., Degel, J., \& PIPER, D. (2002). Proactive and retroactive interference in implicit odor memory. Chemical Senses, 27, 191-206.

LAWLESs, H., \& ENGEN, T. (1977). Associations to odors: Interference, mnemonics, and verbal labeling. Journal of Experimental Psychology: Human Learning \& Memory, 3, 52-59.

Macmillan, N. A., \& Creelman, C. D. (1991). Detection theory: A user's guide. New York: Cambridge University Press.

MacRae, A. W., \& Geelhoed, E. N. (1992). Preference can be more powerful than detection of oddity as a test of discriminability. Perception \& Psychophysics, 51, 179-181.

MAIR, R., CAPRA, C., McEnTEE, W. J., \& ENGEN, T. (1980). Odor discrimination and memory in Korsakoff's psychosis. Journal of Experimental Psychology: Human Perception \& Performance, 6, 445-458.

MasuoKa, S., Hatjopoulos, D., \& O'Mahony, M. (1995). Beer bitterness detection: Testing Thurstonian and sequential sensitivity analysis models for triad and tetrad methods. Journal of Sensory Studies, 10, 295-306.

McBurney, D. H., Kasschau, R. A., \& Bogart, L. M. (1967). The effect of adaptation on taste jnds. Perception \& Psychophysics, 2, 175-178.

Miller, J. (1996). The sampling distribution of $d^{\prime}$. Perception \& Psychophysics, 58, 65-72.

O'MAHONY, M. (1979). Salt taste adaptation: The psychophysical effects of adapting solutions and residual stimuli from prior tastings on the taste of sodium chloride. Perception, 8, 441-476.

O'MAhony, M., \& Goldstein, L. (1986). Effectiveness of sensory difference tests: Sequential sensitivity analysis for liquid food stimuli. Journal of Food Science, 51, 1550-1553.

O'MAHONY, M., MASUOKA, S., \& IsHII, R. (1994). A theoretical note on difference tests: Models, paradoxes and cognitive strategies. Journal of Sensory Studies, 9, 247-272.

O'MAHOny, M., \& OdBert, N. (1985). A comparison of sensory difference testing procedures: Sequential sensitivity analysis and aspects of taste adaptation. Journal of Food Science, 50, 1055-1058.

O’Mahony, M., \& Rousseau, B. (2003). Discrimination testing: A few ideas, old and new. Food Quality \& Preference, 14, 157-164.
Rousseau, B., \& ENNIS, D. M. (2001). A Thurstonian model for the dual-pair (4IAX) discrimination method. Perception \& Psychophysics, 63, 1083-1090.

Rousseau, B., Meyer, A., \& O'Mahony, M. (1998). Power and sensitivity of the same-different test: Comparison with triangle and duo-trio methods. Journal of Sensory Studies, 13, 149-173.

Rousseau, B., \& O’Mahony, M. (1997). Sensory difference tests: Thurstonian and SSA predictions for vanilla flavored yogurts. Journal of Sensory Studies, 12, 127-146.

Rousseau, B., \& O'MAHONY, M. (2000). Investigation of the effect of within-trial retasting and comparison of the dual-pair, same-different and triangle paradigms. Food Quality \& Preference, 11, 457-464.

Rousseau, B., \& O'MAHONY, M. (2001). Investigation of the dual-pair method as a possible alternative to the triangle and same-different tests. Journal of Sensory Studies, 16, 161-178.

Rousseau, B., Rogeaux, M., \& O’Mahony, M. (1999). Mustard discrimination by same-different and triangle tests: Aspects of irritation, memory and $\tau$ criteria. Food Quality \& Preference, 10, 173-184.

Rousseau, B., Stroh, S., \& O’MAHONY, M. (2002). Investigating more powerful discrimination tests with consumers: Effects of memory and response bias. Food Quality \& Preference, 13, 39-45.

Stevenson, R. J., \& Prescott, J. (1997). Judgments of chemosensory mixtures in memory. Acta Psychologica, 95, 195-214.

StILlman, J. A. (1993). Response selection, sensitivity, and taste-test performance. Perception \& Psychophysics, 54, 190-194.

Stillman, J. A., \& IrWIN, R. J. (1995). Advantages of the samedifferent method over the triangular method for the measurement of taste discrimination. Journal of Sensory Studies, 10, 261-272.

Tedja, S., NonaKa, R., Ennis, D. M., \& O’Mahony, M. (1994). Triadic discrimination testing: Refinement of Thurstonian and sequential sensitivity analysis approaches. Chemical Senses, 19, 279-301.

Thurstone, L. L. (1927). A law of comparative judgment. Psychological Review, 34, 273-286.

WALK, H. A., \& JOHNS, E. E. (1984). Interference and facilitation in shortterm memory for odors. Perception \& Psychophysics, 36, 508-514.

White, T. L. (1998). Olfactory memory: The long and short of it. Chemical Senses, 23, 433-441. 


\section{APPENDIX \\ Thurstonian Model Accounting for the Increase of Perceptual Variance Due to Memory Effects in Experiment 1}

The data used here are those from Protocol 1 (no intermediate rinse and no delay) and Protocol 3 (intermediate rinse and time delay) in Experiment 1. As was described in O'Mahony and Rousseau (2003), an approach to calculating $d^{\prime}$ values in the same-different paradigm is to consider the distribution of intensity differences arising from the presentation of pairs of stimuli in the same-different test. These stimuli are assumed to have normal perceptual distributions of intensities of equal variance (cf. Figure A1). Values of $d^{\prime}$ and $\tau$ (the cognitive criterion used by the subject to generate an answer) are estimated on the basis of the variance of these distributions.

Figures A1 and A2 illustrate the relationship between $d_{1}^{\prime}$ and $d_{3}^{\prime}$, the $d^{\prime}$ values associated with Protocol 1 and Protocol 3, respectively. In each figure, the top distributions are related to Protocol 1, whereas the bottom distributions are related to Protocol 3.

Figure A1 represents perceptual distributions of intensities. The distributions associated with Protocol 1 are assumed to have a variance of 1 and to be centered at $X$ and $Y$. In Protocol 3, memory effects increase the variance of the distributions by a factor $m$, so that although they are still centered at $X$ and $Y$, their associated variance is now $1 * m$.

When pairs of identical and different stimuli are presented, three difference distributions can be considered. They are cen- tered at $X-Y, 0$ and $Y-X$, respectively. They have variances equal to the sum of the variances of the intensity distributions from which they originate. Consequently, the difference distributions for Protocol 1 have a variance of 2, whereas the difference distributions for Protocol 3 have a variance of $2 * m$. This is shown in Figure A2.

Figure A2 also illustrates the parameters involved in sample evaluation, such as the $\tau$ criterion (a perceived difference larger than $\tau$ will yield a different answer; otherwise, same). As with the means of the distributions, the location of $\tau$ is assumed to stay constant between the two protocols. This assumption seems appropriate, since both protocols were performed in the same session and the order of presentation of their respective four pairs was randomized over all protocols. Because of the larger variance for Protocol $3(2 * m)$, the estimated $d^{\prime}$ and $\tau$ values for the bottom situation will be lower than those from Protocol 1 with the smaller variance (2), since they are measured in terms of the distributions' variance.

As can be seen in Figure A2, the main change in proportion of same and different responses on passing from Protocol 1 to Protocol 3 comes from the decrease of same answers, with an associated increase in different answers, when the stimuli were identical (greater white areas in the lower left-hand distribution). The relative proportions of same and different answers
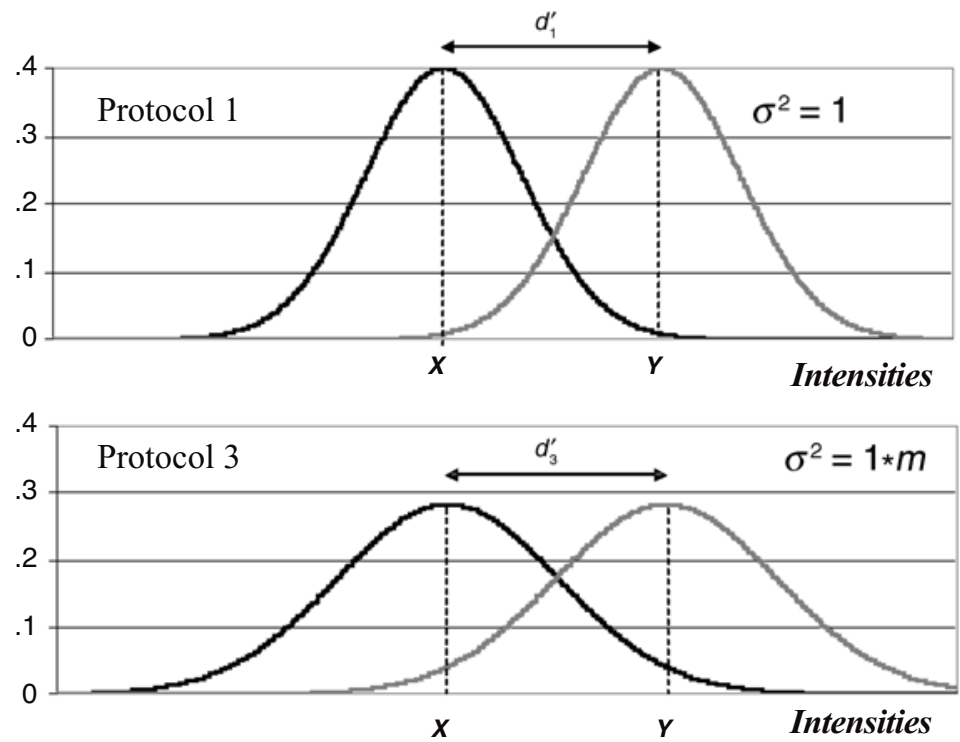

Figure A1. Perceptual distribution of intensities associated with Protocols 1 and 3 , respectively. 


\section{APPENDIX (Continued)}

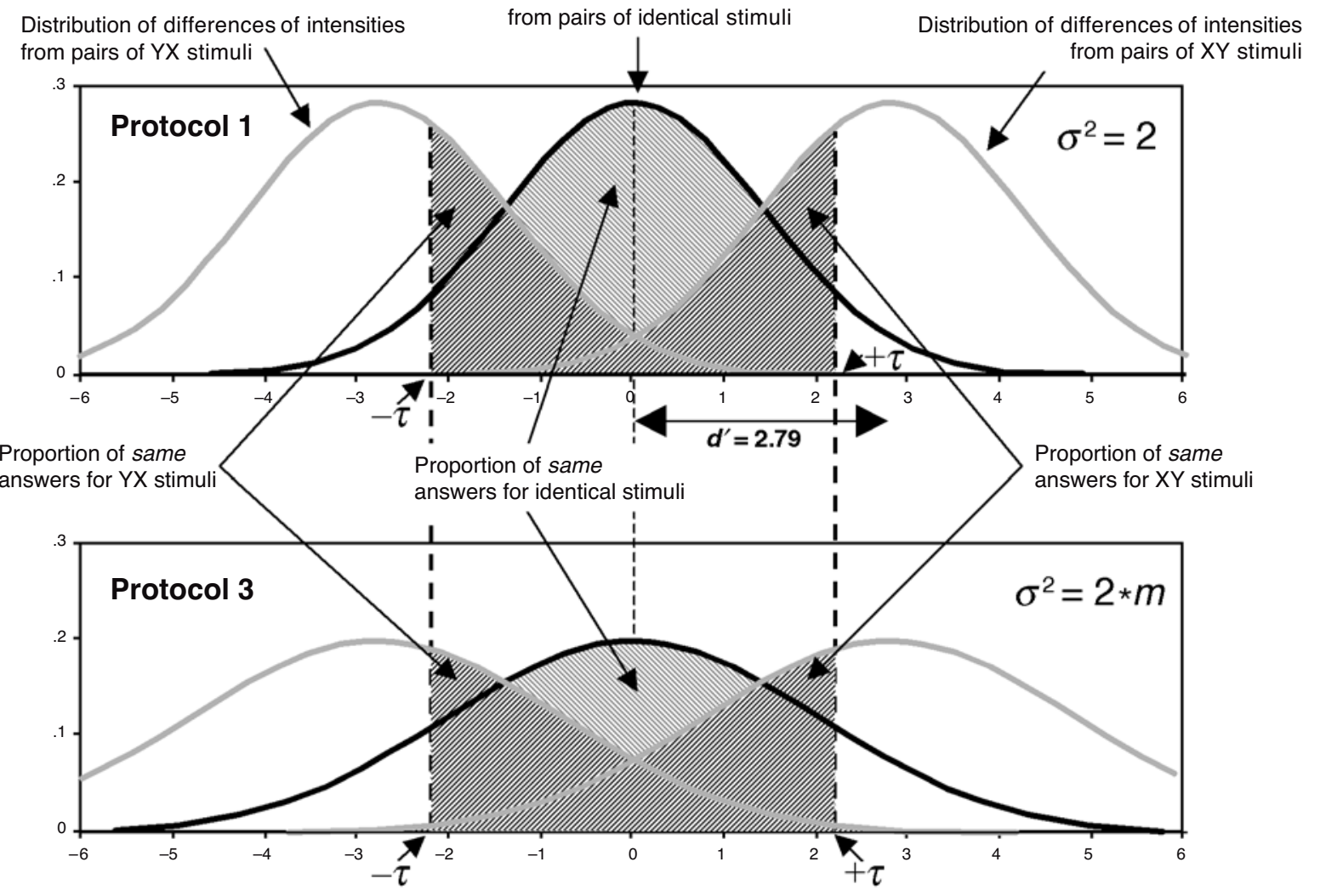

Figure A2. Effect of memory on variance of the distribution of perceived differences in the same-different task (top figure, memory effects minimized; bottom figure, memory effect not negligible). The unit for the $d^{\prime}$ value of 2.79 is the standard deviation of the underlying perceptual distribution of intensities, which have a variance of 1 (here, distributions of differences are represented with a variance of 2 ).

when the stimuli were different does not seem to change to the same extent. This would confirm the results reported in Table 2.

A corroboration of this is provided when the $d^{\prime}$ values obtained in the various protocols and their associated $\tau$ criteria are compared. Given the data from Table 2, we find that the estimated $d^{\prime}$ and $\tau$ values for Protocol 1 are 2.79 and 2.21, respectively, whereas those for Protocol 3 are 2.20 and 1.71, respectively (the $d^{\prime}$ values are slightly different from those reported in Table 2, since the response frequencies used [same and different] result from combining two categories [same sure and same unsure, on the one hand, and different sure and different unsure, on the other hand).

Normalizing the distance $Y-X$ according to the variance of the distributions, we find $d_{1}^{\prime}$ and $d_{3}^{\prime}$ with

$$
d_{1}^{\prime}=\frac{Y-X}{\sqrt{2}} \text { and } d_{3}^{\prime}=\frac{Y-X}{\sqrt{2 * m}} \text {. }
$$

Consequently, we find

$$
d_{3}^{\prime}=\frac{d_{1}^{\prime}}{\sqrt{m}} .
$$

From Equation A1, we find that $m=1.61$.

The same relationship as that described in Equation A1 applies to the size of the $\tau$ criteria. With $\tau_{1}=2.21$ and $m=1.61$, we deduce $\tau_{3}=1.74$, as compared with an actual value of 1.71 estimated from the data.

Therefore, a simple Thurstonian model with an extra parameter (the variance-increasing factor $m$ ) successfully accounts for the effect of memory on the response categories in the same-different test (main change in proportion when increasing the memory requirements will be for the proportion of same answers for identical samples to decrease). It does so without the assumption that the subjects used a different decision rulethat is, different $\tau$ criteria. 